\title{
Clinical conditions responsible for hyperviscosity and skin ulcers complications
}

\author{
Gregorio Caimi*, Baldassare Canino, Rosalia Lo Presti, Caterina Urso and Eugenia Hopps \\ Dipartimento Biomedico di Medicina Interna e Specialistica, Università di Palermo, Italy
}

\begin{abstract}
In this brief review, we have examined some clinical conditions that result to be associated to an altered hemorheological profile and at times accompanied by skin ulcers. This skin condition may be observed in patients with the following condtions, such as primary polycythemic hyperviscosity (polycythemia, thrombocytemia) treated with hydroxyurea, primary plasma hyperviscosity (multiple myeloma, cryoglobulinemia, cryofibrinogenemia, dysfibrinogenemia, and connective tissue diseases), primary sclerocythemic hyperviscosity (hereditary spherocytosis, thalassemia, and sickle cell disease). In addition, it may be present in patients with secondary hyperviscosity conditions such as diabetes mellitus, arterial hypertension, critical limb ischemia and chronic venous insufficiency.
\end{abstract}

Keywords: Hyperviscosity syndrome, blood viscosity, skin ulcers

\section{Introduction}

The blood flow differs from that running through microvessels and that through large vessels. These differences refer to the blood composition, haemodynamics, and specifically blood viscosity. Rheological alterations play a prominent role in microcirculation than in large vessels haemodynamics. When a potentially ischemic condition emerges, some changes develop in microcirculation in relation to the diameter and the wall permeability of microvessel, the cell metabolism and the haemorheological profile. Physiologically, the blood flow is influenced by blood velocity, vessel diameter, structure and blood viscosity. As for the blood viscosity, this is determined by the haematocrit, the plasma viscosity, and the red cell aggregation and deformability. Blood viscosity varies in relation with the shear rate. Results have clearly demonstrated that red cell deformability and plasma viscosity are very significant at high shear flow while red cell aggregation occurs at low shear flow.

\section{Primary hyperviscosity condition}

Primary hyperviscosity condition may be subdivided into polycythemic, plasma and sclerocythemic $[8,21,26,58,59]$.

Skin ulcers are uncommon in polycythemic hyperviscosity caused generally by the bone marrow proliferative states (polycythemia, thrombocytemia, leukemia). Skin ulcers, nevertheless, may be caused

\footnotetext{
*Corresponding author: Prof. Gregorio Caimi, Dipartimento Biomedico di Medicina Interna e Specialistica, Università degli Studi di Palermo, Via del vespro 129, Palermo 90100, Italy. Tel.: +39 091 6554406; Fax: +39 091 6554535; E-mail: gregorio.caimi@unipa.it.
} 
by the treatment with hydroxyurea (DNA synthase inhibitor) in patients with polycythemia and thrombocytemia. Their pathogenesis is not clear, but there is a possible connection with a direct toxicity of this chemotherapeutic agent on the skin. According to other authors, skin ulcers are instead related to the prolonged use of this molecule [35, 41, 48, 82], even if previously had been demonstrated that this molecule acts on erythrocyte geometry and deformability [30].

Patients with plasma hyperviscosity may be affected by skin ulcers; this hemorheological disorder is most often associated with paraproteinemias, which are clinical condition characterized by the presence of an abnormal immunoglobulin secreted by malignant B-lymphoid cells of monoclonal origin. In some cases, more than one monoclonal paraprotein is present in the same patient and in some instances the paraprotein is the immunoglobulin light chain, while in fewer cases it is the heavy chain.

Multiple myeloma (MM) and Waldenstom's macroglobulinemia (WM) are blood diseases complicated with paraproteinemias; in MM patients there may be the presence of skin ulcers [25, 86]. One of our studies (unpublished data) carried out in a group of MM patients has highlighted not only an increase in plasma viscosity (especially at low shear rate) and a decrease in haematocrit, but also a reduction in erythrocyte deformability. This data may be explained by the alteration of the lipid composition demonstrated in the erythrocyte membrane and in the plasma of MM patients [46, 104]. In addition, an alternative hypothesis may be explained by the presence of a paroxysmal nocturnal hemoglobinuria-like defect in the erythrocyte membrane of MM subject group [19, 64, 94, 100].

Cryoglobulinemia is a clinical condition in which the presence of plasma hyperviscosity may be associated with skin ulcers and in particular with leg ulcers. Cryoglobulinemia is due to the presence in the plasma or in the serum of one or more immunoglobulins which precipitate at a temperature below $37^{\circ} \mathrm{C}$ and redesolve on rewarming. The composition of cryoglobulins is heterogeneous. Three basic types are recognized according to the clonality and the type of immunoglobulins. Type I consist of monoclonal immunoglobulins, generally either IgM or IgG. Type II is an association of monoclonal IgM and polyclonal IgG. Type III is a mixture of polyclonal IgM and polyclonal IgG. Type II and III are described as mixed cryoglobulinemia because they consist of polyclonal IgG and IgM [74].

A percentage of $2 \%$ to $50 \%$ of patients affected by circulating cryoglobulins develop clinical symptoms. At the onset of the disease the most frequent symptoms found on $80 \%$ of patients are purpura, arthralgia and weakness.

Ferri et al. demonstrated an alteration in plasma and serum viscosity and in cellular filtration index in a subject group with mixed cryoglobulinemia at $37^{\circ} \mathrm{C}$ and at $25^{\circ} \mathrm{C}$ [31]. In several papers regarding mixed cryoglobulinemia the presence of skin ulcers has been observed [5, 32, 33, 37, 78, 108]. The hemorheological alteration influences and worsens the skin ulcers through tissue ischemia even if the mixed cryoglobulinemia is a systemic vasculitis and the hemorheological impairment may favor the immunological damage in the vessel wall. The outcome of the clinical history of patients with mixed cryoglobulinemia depends on the presence of possible concomitant diseases and complications and on their response to treatment.

Cryofibrinogenemia, primary or secondary, is a rare disorder characterized by cryoprecipitation of the native fibrinogen in the plasma, which can cause thrombotic occlusions of the small to medium arteries [65, 83]. Clinically, it is possible to distinguish patients with isolated or primary cryofibrinogenemia from those with associated cryoglobulinemia. Patients with primary cryofibrinogenemia suffered more frequently from recurrent and necrotic skin lesions [76]. The mean concentration of plasma cryoprecipitate is generally higher in patients with primary cryofibrinogenemia. This clinical condition causes a variety of skin manifestation, including skin ulceration $[3,9-11,51,81,84,85,106]$.

Cryofibrinogenemia is a treatable and potentially reversible disease. The use of corticosteroids in association with low-dose aspirin is considered the specific treatment of moderate forms, even if stanozolol results an alternative therapy. Immunosoppressive therapy, plasmapheresis, and/or intravenous fibrinolysis are useful for treating some severe forms of cryofibrinogenemia. 
Dysfibrinogenemias are clinical disorders in which a condition of plasma hyperviscosity has been found [51, 67]. Dysfibrinogenemias are characterized by structural abnormalities in the fibrinogen molecule that alters its functional properties [2, 42, 43, 79]. As previously demonstrated, the diagnosis of dysfibrinogenemia is related to a fibrinogen with abnormal structure or function. Generally, a dysfibrinogenemia may be found by discovering an abnormal thrombin time, with or without an abnormal reptilase time. The presence of a dysfibrinogenemia is suggested by a normal or increased immunologic level of fibrinogen with a lower functional level. Congenital dysfibrinogenemia is caused by heterozygosity for a mutation within any of the three fibrinogen chain genes. Acquired dysfibrinogenemia is a rare abnormality that may be found in patients with conditions such as: liver disease, multiple myeloma, autoimmune disorders and cancer [99].

Clinically, subjects with dysfibrinogenemia (congenital or not) are frequently asymptomatic (55\%) even if some subjects will exhibit bleeding (25\%), thrombotic complications (20\%), or both, and among the thrombotic complications, skin necrosis may be discovered [18, 89].

Skin ulcers may be present in patients with connective tissue diseases, not only in systemic sclerosis, but also in rheumatoid arthritis, systemic lupus erythematosus and in ankylosing spondylitis [20, 27, 39, 69, 87, 88, 92, 103]. In all these clinical conditions the rheological abnormality [57, 80], has been attributed to the presence of some protein of polyclonal origin. In previous studies regarding connective tissue diseases, data demonstrates an increase in plasma and serum viscosity, and in erythrocyte aggregation; in some cases also a decrease in whole-blood filtration has been detected. All these clinical conditions are characterized by an evident increase in plasma viscosity that may explain the alteration of the skin microvascular blood flow, even if its direct effect might be mitigated by the increase in endothelial nitric oxide synthesis, that reduces the vascular resistance [97]. Plasma viscosity, in fact, controls the blood flow resistance, which regulates the vascular tone and preserves the functional capillary density $[13,98]$. The impairment of this microcirculatory aspect may contribute to the pathogenesis of skin ulcers.

In sclerocythemic hyperviscosity, the presence of chronic and refractory skin ulcers can be often present in some diseases, such as hereditary spherocytosis, thalassemia and sickle cell diserce.

Hereditary spherocytosis is a common inherited disorder characterized by anemia, j@ce and splenomegalia. The primary erythrocyte alteration of this type of anemia is the loss of membrane surface area, leading to a reduced deformability referable to the defects in the membrane proteins such as ankirin, band 3, $\beta$-spectrin, $\alpha$-spectrin or protein $4.2[7,57,61,72]$.

An uncommon complication of spherocytosis is the refractory chronic leg ulcer (2\%) that heals after splenectomy $[1,73]$. From the study based on two patients (father and son) affected by spherocytosis who had already undergone a splenectomy, we found an increase in whole-blood viscosity at low shear rate, a decrease in whole-blood filtration and especially a reduction in elongation index evaluated with laser diffractometry.

Thalassemia is a congenital haemoglobinopathy caused by defective synthesis of the $\alpha$ or $\beta$ hemoglobin chains. $\beta$-thalassemias are a group of hereditary blood disorders characterized by anomalies in the synthesis of the $\beta$-chain. $\beta$-thalassemias can be classified into major, intermedia, minor and carriers $[17,36]$. In $\beta$-thalassemia major [60] there is an evident decrease in whole-blood viscosity at low shear rate, a reduction in hematocrit and an increase in erythrocyte rigidity without any variation of plasma viscosity. As for the $\beta$-thalassemia intermedia [34] there is a significant decrease in hematocrit and in whole-blood filtration. In relation to the $\beta$-thalassemia minor [71] there is a reduction in the relaxation time and in the erythrocyte deformability, without any significant variation of elastic modul and surface viscosity. The $\beta$-thalassemia carriers [101] present a decrease in the elongation index and in the erythrocyte aggregation; patients with $\beta$-thalassemia intermedia may have painful, indolent and refractory leg ulcers [12, 53, 68]. 
Sickle cell disease is a genetic disorder of the haemoglobin (homozigous HBB val6) responsible for acute deep tissue damage, such as vaso-occlusive crisis, acute chest syndrome and spleen infarction and for chronic involvement regarding bones, kidney and skin. [4, 6, 73, 102, 104].

Previous studies highlight the disabling complication and the severity indicator of sickle cell skin ulcers [45]. There are several reports that indicate how in sickle cell disease (SCA) there is an evident alteration of the hemorheological pattern $[57,68]$. Hemorheologically patients with SCA present a decrease in the hematocrit, in the whole-blood viscosity at low and high shear rates, in the aggregation index and especially in the elongation index. In addition, some hemorheological parameters and some hemorheological indexes (except for the hematocrit), seem to discriminate SCA patients with frequent crisis from those with infrequent crisis.

Our study based on a small number of patients with microdrepanocytosis highlighted an evident decrease in erythrocyte deformability, examined with laser diffractometry. A programmed erythrocytapheresis treatment was conducted on SCA patients and it has demonstrated to control and improve the acute and chronic complications accompaning this clinical condition [29, 47].

All these clinical disorders (hereditary spherocytosis, $\beta$-thalassemia, sickle cell disease) are marked out by an evident decrease in erythrocyte deformability, which acts in the microcirculatory zone through an obstructive mechanism and also influences the oxygen delvery to tissue $[8,28,70,107]$; both these components contribute to the pathogenesis of skin ulcers.

\section{Secondary hyperviscosity condition}

Diabetes mellitus, arterial hypertension, critical limb ischemia and chronic venous insufficiency are among the diseases that may cause a secondary hyperviscosity condition and skin ulcers.

Our studies related to these disorders have discovered the presence of an alteration of the hemorheological profile. This is characterized by an increase in whole-blood, plasma and serum viscosity, by an increase in red cell aggregation, and by a decrease in erythrocyte deformability. In addition, our investigation using the spectroscopic fluorescence and employing fluorescent probes, found evident alterations of the erythrocytes and polymorphonuclear membrane rheology [14-16, 45, 55, 56].

The clinical course and the treatment of diabetic foot syndrome (ischemia, ulcers, gangrene) obtained with fibrinogen adsorption [50] or with Heparin-induced extracorporal LDL Precipitation (HELP) improves the prognosis of the ulcers of diabetic patients [76, 77, 105]. Diabetic foot syndrome is a complication of long-standing diabetes. The combination of macrovascular and microvascular disease associated with neuropathy leads to the development of leg ulcers.

A microvascular disease worsens with the increase in plasma viscosity and the decrease in red cell deformability, as observed in diabetes mellitus conditions. The increase in plasma viscosity may be explained by the presence of hyperfibrinogenemia. Factors influencing erythrocyte deformability in diabetes mellitus are: decrease in the surface/volume ratio related to the sorbitol cytosolic accumulation and to the membrane lipid alterations, increase in the cytosolic viscosity related to the reduction in the organic phosphates, increase in the calcium and glycated hemoglobin, alteration of the membrane dynamic properties related to the qualitative and/or quantitative membrane alterations of lipids and proteins.

To be underlined is the association of the diabetic disease with thrombocytopathy related to the increased platelet adhesiveness and aggregability; these laboratory findings are present in this metabolic condition before the development of vascular lesions and depend on poor metabolic control. The increase in platelet aggregation found in diabetic subjects aggravates the microcirculatory blood flow and slows down the healing of skin necrosis.

All these hemorheological and coagulative alterations described in diabetes are decisive for the microcircolatory disorders. Moreover it must be underlined that the increase in glycated hemoglobin, 
besides reducing the erythrocyte deformability, shifts the hemoglobn dissociation curve and diminbishes the P50. This latter certainly acts negatively on the oxygen transport and contributes to the skin lesion.

Moreover, the arterial hypertension may be associated with skin ulcers (Martorell's ulcers), frequently symmetric and located in the distal third and anterolateral surface of the lower limbs [38, 54, 102]. Martorell's ulcers are noticeable for their painful red blisters, which soon become blue, purpuric and finally ulcerate. These ulcers may be preceeded by "pigmented pretibial patches". Pain, relented healing and poor clinical response to standard therapy are a distinguishing sign of Martorell's ulcers. The study of microcirculation shows an increase in resistance of the arterioles associated to a limited compensatory mechanism. Other causal factors in the genesis of these ulcers may be the alterations in the sympathetic innervation, a persistent arteriolar hypertonia and an abnormal arteriolar vascular response to vasoactive substances. The impaired hemorheological profile has a possible role in the clinical course of these ulcers and may contribute to the organic complications of arterial hypertension, such as left ventricular hypertrophy and retinopathy. Another interesting point is related to the abnormalities in hemorheological parameters, which are observed mainly in the high-renin than in low-renin hypertensive subjects. In essential hypertension the impaired tissue oxygenation, that seems to accompany this clinical condition, may have a role in the pathogenesis of skin lesions.

In peripheral arterial disease and especially in subjects with non-diabetic and non-hypertensive critical limb ischemia, the hemorheological alteration is ascribable especially to the erythrocyte rigidity and after arterial reconstruction there seems to be no improvement in the hemorheological profile [44, $49,90]$. However, the importance of the hemorheological profile in critical leg ischaemia refers to the negative results that blood viscosity and fibrinogen levels have on the intermittent claudication, as well as the negative prognostic significance of hemoglobin levels in the healing of amputations due to critical leg ischaemia, including the negative prognostic significance of fibrinogen in critical leg ischaemia. There is a break between the microvascular flow and the microvascular defence systems in patients with critical leg ischaemia. A more rapid and evident rheological effect may be obtained by the prescription of normovolemic hemodilution, pharmacological defibrinogenation and plama exchange. In crtical leg ischemia the pathogenesis of skin ulcers results to be complex: endothelial injury, and neutrophil and platelet activation, that influence the hemorheological pattern, might be responsible for the damage in microcirculation $[23,24]$.

The progression of chronic venous insufficiency may develop venous leg ulcers [22]. Persistent venous stasis associated with increased venous pressure develops venous ulcers. The increase in capillary permeability leads to the extravasation of proteins and fibrinogen from the capillaries. High fibrinogen concentration causes a fibrin cuff composition blocking the diffusion of nutrients, an microcirculation impairment and subsequent skin necrosis. In the pathophysiology of these venous ulceration evident is the trapping and the activation of PMN cells; in patients with venous ulcers we observed a decreased PMN membrane fluidity, an increased PMN cytosolic $\mathrm{Ca}^{++}$content and an abnormal response to the PMN integrins (CD11b, CD11c, CD18), especially after in vitro activation with PMA and fMLP [55]. The clinical evolution of the chronic venous insufficiency with skin ulcers is referable not only to the marked microcirculatory disorder, but in particular to the functional alterations of the polymorphonuclear cells $[63,91]$.

\section{Conclusions}

Several clinical conditions responsible for primary or secondary hyperviscosity may be associated with skin ulcers. However, a clear impact of the hemorheological alteration on these ulcers cannot be demonstrated. An acceleration of the healing process of skin ulcers has been obtained through 
pharmacological treatment, plasma exchange, erythroapheresis or fibrinogen adsorption (rheosorb). Consequently, resulting in an improvement of the hemorheological profile.

\section{References}

[1] F. Abdullah, Y. Zhang, M. Camp, M.I. Rossberg, M.A. Bathurst, P.M. Colombani, J.F. Casella, R. Nabaweesi and D.C. Chang, Splenectomy in hereditary spherocytosis: Review of 1,657 patients and application of the pediatric quality indicators, Pediatr Blood Cancer 52(7) (2009), 834-837.

[2] S.S. Acharya and D.M. Dimichele, Rare inherited disorders of fibrinogen, Haemophilia 14(6) (2008), 1151-1158.

[3] T.D. Amdo and J.A.Welker, An approach to the diagnosis and treatment of cryofibrinogenemia, Am J Med 116(5) (2004), 332-337.

[4] M. Amini-Adle, C. Auxenfants, C. Allombert-Blaise, M.C Deroo-Berger, A. Ly, D. Jullien, M. Faure, O. Damour and A. Claudy, Rapid healing of long-lasting sickle cell leg ulcer treated with allogeneic keratinocytes, J Eur Acad Dermatol Venereol 21(5) (2007), 707-708.

[5] V. Auzerie, A. Chiali, A. Bussel, J.C. Brouet, J.P. Fermand, L. Dubertret and P. Senet, Leg ulcers associated with cryoglobulinemia: Clinical study of 15 patients and response to treatment, Arch Dermatol 139(3) (2003), 391-393.

[6] S.K. Ballas and N. Mohandas, Sickle red cell microrheology and sickle blood rheology, Microcirculation 11(2) (2004), 209-225.

[7] W. Barcellini, P. Bianchi, E. Fermo, F.G. Imperiali, A.P. Marcello, C. Vercellati, A. Zaninoni and A. Zanella, Hereditary red cell membrane defects: Diagnostic and clinical aspects, Blood Transfus 9(3) (2011), 274-277.

[8] O.K. Baskurt, M.R. Hardeman, M.W. Rampling and H.J. Meiselman (Ed), Handbook of hemorheology and hemodynamics. Biomedical and Health Research: IOS Press; 2007.

[9] P. Begin and G. Leclerc, Images in clinical medicine. Familial primary cryofibrinogenemia, $N$ Engl J Med 369(8) (2013), e10.

[10] E. Beightler, D.G. Diven, R.L. Sanchez and A.R. Solomon, Thrombotic vasculopathy associated with cryofibrinogenemia, J Am Acad Dermatol 24(2 Pt 2) (1991), 342-345.

[11] H. Blain, P. Cacoub, L. Musset, N. Costedoat-Chalumeau, C. Silberstein, O. Chosidow, P. Godeau, C. Frances and J.C. Piette, Cryofibrinogenaemia: A study of 49 patients, Clin Exp Immunol 120(2) (2000), 253-260.

[12] C. Borgna-Pignatti, M. Marsella and N. Zanforlin, The natural history of thalassemia intermedia, Ann N Y Acad Sci 1202 (2010), 214-220.

[13] P. Cabrales and A.G. Tsai, Plasma viscosity regulates systemic and microvascular perfusion during acute extreme anemic conditions, Am J Physiol Heart Circ Physiol 291 (2006), H2445-2452.

[14] G. Caimi, R. Lo Presti, B. Canino, F. Ferrara, M. Montana, G. Ventimiglia, A. Catania, M. Cospite and A. Sarno, Leukocyte flow properties, polymorphonuclear membrane fluidity and cytosolic $\mathrm{Ca} 2+$ content in subjects with vascular atherosclerotic disease, Artery 22(6) (1997), 328-335.

[15] G. Caimi, R. Lo Presti, M. Montana, A. Serra, G. Grifò, B. Canino, A. Catania and A. Sarno, Diabetes mellitus: Mean erythrocyte aggregation, glycometabolic pattern, red cell $\mathrm{Ca} 2+$ content, and erythrocyte membrane dynamic properties, Microvasc Res 46(3) (1993), 401-405.

[16] G. Caimi, R. Lo Presti, C. Carollo, M. Musso, F. Porretto, B. Canino, A. Catania and G. Cerasola, Polymorphonuclear integrins, membrane fluidity, and cytosolic $\mathrm{Ca}(2+)$ content after activation in essential hypertension, Hypertension 36(5) (2000), 813-817.

[17] C. Camaschella and M.D. Cappellini, Thalassemia intermedia, Haematologica 80(1) (1995), 58-68.

[18] A. Casini, M. Blondon, A. Lebreton, J. Koegel, V. Tintillier, E. de Maistre, P. Gautier, C. Biron, M. Neerman-Arbez and P. de Moerloose, Natural history of patients with congenital dysfibrinogenemia, Blood 125(3) (2015), 553-561.

[19] V. Chatziantoniou, S. Alexia, K. Konstantopoulos, P. Repousis, A. Megalakaki, M. Kotsopoulou, P. Kylidou, T. Vassilakopoulos and M.K. Angelopoulou, Significance of the detection of paroxysmal nocturnal hemoglobinuria clones in patients with multiple myeloma undergoing autologous stem cell transplantation, Hematol Oncol Stem Cell Ther 8(4) (2015), 150-159.

[20] H.Y. Chia and M.B. Tang, Chronic leg ulcers in adult patients with rheumatological diseases - a 7-year retrospective review, Int Wound J 11(6) (2014), 601-604.

[21] S. Chien, J. Dormandy, E. Ernst and A. Matrai (Ed), Clinical Hemorheology. Dordrecth: Nijhoff; 1987.

[22] A. Comerota and F. Lurie, Pathogenesis of venous ulcer, Semin Vasc Surg 28(1) (2015), 6-14.

[23] P. Danielsson, L. Truedsson and L. Norgren, Systemic white blood and endothelial cell response after revascularization of critical limb ischemia is only influenced in case of ischemic ulcers, Int Angiol 25(3) (2006), 310-315. 
[24] P. Danielsson, G. Danielsson, L. Truedsson and L. Norgren, White blood cell and endothelial cell response to endovascular procedures in the leg, Int Angiol 23(2) (2004), 122-127.

[25] M.S. Daoud, J.A. Lust, R.A. Kyle and M.R. Pittelkow, Monoclonal gammopathies and associated skin disorders, J Am Acad Dermatol 40(4) (1999), 507-535.

[26] T. Di Perri, S. Forconi, F. Di Lollo and G. Pozza, Le sindromi da iperviscosità ematica. In: Atti dell' $84^{\circ}$ Congresso della Società Italiana di Medicina Interna. Roma: Pozzi; 1983:193-310.

[27] M. Doveri, A. Della Rossa, S. Salvadori, A. D’Ascanio, A. Tavoni, L. Bazzichi, et al., Systemic sclerosis: Outcome and long term follow-up of 429 patients from a single italian centre, Ann Rheum Dis 70(Suppl 3) (2011), 660.

[28] G.K. Driessen, C.W. Haest, H. Heidtmann, D. Kamp and H. Schmid-Schonbein, Effect of reduced red cell deformability on flow velocity in capillaries of rat mesentery, Pflugers Arch 388 (1980), 75-78.

[29] F. Driss, J. Moh-Klaren, A.M. Pela, G. Tertian, Regular automated erythrocytapheresis in sickle cell patients, $B r J$ Haematol 154(5) (2011), 656-659.

[30] K.G. Engström and E. Löfvenberg, Treatment of myeloproliferative disorders with hydroxyurea: Effects on red blood cell geometry and deformability, Blood 91(10) (1998), 3986-3991.

[31] C. Ferri, L. Mannini, V. Bartoli, G. Gremignai, F. Genovesi-Ebert, R. Cristofani, B. Albanese, G. Pasero and S. Bombardieri, Blood viscosity and filtration abnormalities in mixed cryoglobulinemia patients, Clin Exp Rheumatol 8(3) (1990), 271-281.

[32] C. Ferri, M. Sebastiani, D. Giuggioli, M. Cazzato, G. Longombardo, A. Antonelli, R. Puccini, C. Michelassi and A.L. Zignego, Mixed cryoglobulinemia: Demographic, clinical, and serologic features and survival in 231 patients, Semin Arthritis Rheum 33(6) (2004), 355-374.

[33] C. Ferri, Mixed cryoglobulinemia, Orphanet J Rare Dis 3 (2008), 25.

[34] G. Fiorelli, F. Turrini, F. Mannu, F. Porro, G. Graziadei, D. Tavazzi, L. Duca and M.D. Cappellini, Erythrocyte membrane alterations in thalassemia intermedia, Clin Hemorheol 16 (1996), 789-797.

[35] E.R. França, M.A. Teixeira, F. Matias Kde, D.E. Antunes, A. Braz Rde and C.E. Silva, Cutaneous effects after prolongaded use of hydroxyurea in Polycythemia Vera, An Bras Dermatol 86(4) (2011), 751-754.

[36] R. Galanello and R. Origa, Beta-thalassemia, Orphanet J Rare Dis 5 (2010), 11.

[37] D. Giuggioli, A. Manfredi, F. Lumetti, M. Sebastiani and C. Ferri, Cryoglobulinemic vasculitis and skin ulcers. Our therapeutic strategy and review of the literature, Semin Arthritis Rheum 44(5) (2015), 518-526.

[38] J.W. Graves, J.C. Morris and S.G. Sheps, Martorell's hypertensive leg ulcer: Case report and concise review of the literature, J Hum Hypertens 15(4) (2001), 279-283.

[39] E. Hachulla, P. Clerson, D. Launay, M. Lambert, S. Morell-Dubois, V. Queyrel and P.Y. Hatron, Natural history of ischemic digital ulcers in systemic sclerosis: Single-center retrospective longitudinal study, J Rheumatol 34(12) (2007), 2423-2430.

[40] M. Halabi-Tawil, F. Lionnet, R. Girot, C. Bachmeyer, P.P. Lévy and S. Aractingi, Sickle cell leg ulcers: A frequently disabling complication and a marker of severity, Br J Dermatol 158(2) (2008), 339-344.

[41] I. Hanchi, F. Zeglaoui, N. Ezzine, L. Daoud, M. Karoui, B. Fazaa and M. Ridha Kamoun, Leg ulcer in a patient treated with hydroxyurea for polycythemia vera, Presse Med 35(7-8) (2006), 1174-1176.

[42] T. Hayes, Dysfibrinogenemia and thrombosis, Arch Pathol Lab Med 126(11) (2002), 1387-1390.

[43] M. Hill and G. Dolan, Diagnosis, clinical features and molecular assessment of the dysfibrinogenaemias, Haemophilia 14(5) (2008), 889-897.

[44] A. Holmberg, B. Sandhagen and D. Bergqvist, Hemorheologic variables in critical limb ischemia before and after infrainguinal reconstruction, J Vasc Surg 31(4) (2000), 691-695.

[45] E. Hopps, A. Camera and G. Caimi, Polimorphonuclear leukocytes and diabetes mellitus, Minerva Med 99(2) (2008), 197-202.

[46] A. Jurczyszyn, J. Czepiel, J. Gdula-Argasińska, P. Paśko, A. Czapkiewicz, T. Librowski, W. Perucki, A. Butrym, J.J. Castillo and A.B. Skotnicki, Plasma fatty acid profile in multiple myeloma patients, Leuk Res 39(4) (2015), 400-405.

[47] A. Kalff, C. Dowsing and A. Grigg, The impact of a regular erythrocytapheresis programme on the acute and chronic complications of sickle cell disease in adults, Br J Haematol 149(5) (2010), 768-774.

[48] T. Kato and S. Kawana, An ulceronecrotic foot lesion in a patient with essential thrombocythemia: Successful treatment with hydroxyurea, Case Rep Dermatol 4(1) (2012), 10-13.

[49] C. Köksal, M. Ercan and A.K. Bozkurt, Hemorrheological variables in critical limb ischemia, Int Angiol 21(4) (2002), 355-359.

[50] R.A. Koll, J. Klinkmann and W.O. Richter, RheoSorb: A specific adsorber for fibrinogen elimination in clinical situations with impaired rheology, Artif Organs 26(2) (2002), 145-151.

[51] H.C. Kwaan, M. Levin, S. Sakurai, O. Kucuk, M.W. Rooney, L.J. Lis and J.W. Kauffman, Digital ischemia and gangrene due to red blood cell aggregation induced by acquired dysfibrinogenemia, J Vasc Surg 26(6) (1997), 1061-1068. 
[52] Y. Lamarre, M. Romana, X. Waltz, M.L. Lalanne-Mistrih, B. Tressières, L. Divialle-Doumdo, M.D. Hardy-Dessources, J. Vent-Schmidt, M. Petras, C. Broquere, F. Maillard, V. Tarer, M. Etienne-Julan and P. Connes, Hemorheological risk factors of acute chest syndrome and painful vaso-occlusive crisis in children with sickle cell disease, Haematologica 97(11) (2012), 1641-1647.

[53] C. Levin and A. Koren, Healing of refractory leg ulcer in a patient with thalassemia intermedia and hypercoagulability after 14 years of unresponsive therapy, Isr Med Assoc J 13(5) (2011), 316-318.

[54] A.P. Lima Pinto, N.A. Silva Jr, C.T. Osorio, L.M. Rivera, S. Carneiro, M. Ramos-E-Silva and B.E. Gomes Bica, Martorell's ulcer: Diagnostic and therapeutic challenge, Case Rep Dermatol 7(2) (2015), 199-206.

[55] R. Lo Presti, F. Ferrara, B. Canino, A. Valenti, F. Raimondi and G. Caimi, Fluidità di membrana, calcio citosolico ed assetto integrinico dei leucociti polimorfonucleati in pazienti con ulcere venose, Min Cardioang 54(suppl) (2006), 246-248.

[56] R. Lo Presti, E. Hopps and G. Caimi, Hemorheological abnormalities in human arterial hypertension, Korea-Australia Rheol J 26 (2014), 199-204.

[57] R. Lo Presti, G. Milio, M. Montana, D. Lucido, F. Raimondi and G. Caimi, Effetti emoreologici del trattamento con iloprost in pazienti con fenomeno di Raynaud secondario a sclerodermia, Min Cardioang 54(suppl) (2006), $221-222$.

[58] G.D.O. Lowe (Ed), Clinical blood rheology. Boca Raton: CRC Press; 1988.

[59] G.D.O. Lowe, M.M. Drummond, C.D. Forbes and J.C. Barbenel, Occlusive arterial disease and blood rheology. In: G.D.O. Lowe, J.C. Barbenel, C.D. Forbes (Ed), Clinical aspects of blood viscosity and cell deformability. Berlin: Springer Verlag; 1981, pp. 133-148.

[60] M. Mangalani, M.R. Lokeshwar, R. Banerjee, K. Nageswari and R.R. Puniyani, Hemorheological changes in blood transfusion-treated beta thalassemia major patients, Clin Hemorheol Microcirc 18(2-3) (1998), 99-102.

[61] M. Mariani, W. Barcellini, C. Vercellati, A.P. Marcello, E. Fermo, P. Pedotti, C. Boschetti and A. Zanella, Clinical and hematologic features of 300 patients affected by hereditary spherocytosis grouped according to the type of the membrane protein defect, Haematologica 93(9) (2008), 1310-1317.

[62] B.N. Matta, O. Abbas, J.E. Maakaron, S. Koussa, R.H. Daderian and A.T. Taher, Leg ulcers in patients with $\beta$ thalassaemia intermedia: A single centre's experience, J Eur Acad Dermatol Venereol 28(9) (2014), 1245-1250.

[63] J.C. McDaniel, S. Roy and T.A.Wilgus, Neutrophil activity in chronic venous leg ulcers-a target for therapy? Wound Repair Regen 21(3) (2013), 339-351.

[64] J. Meletis, E. Terpos, M. Samarkos, C. Meletis, E. Apostolidou, V. Komninaka, K. Korovesis, K. Anargyrou, O. Benopoulou, D. Mavrogianni, E. Variami, N. Viniou and K. Konstantopoulos, Detection of CD55- and/or CD59deficient red cell populations in patients with plasma cell dyscrasias, Int J Hematol 75(1) (2002), 40-44.

[65] M. Michaud and J. Pourrat, Cryofibrinogenemia, J Clin Rheumatol 19(3) (2013), 142-148.

[66] C.P. Minniti, J. Eckman, P. Sebastiani, M.H. Steinberg and S.K. Ballas, Leg ulcers in sickle cell disease, Am J Hematol 85(10) (2010), 831-833.

[67] S. Morsdorf, Haemostatical and rheological aspects of dysfibrinogenemia, Clin Hemorheol Microcirc 17 (1997), 13-19.

[68] D. Nebor, A. Bowers, M.D. Hardy-Dessources, J. Knight-Madden, M. Romana, H. Reid, J.C. Barthélémy, V. Cumming, O. Hue, J. Elion, M. Reid, P. Connes and CAREST Study Group, Frequency of pain crises in sickle cell anemia and its relationship with the sympatho-vagal balance, blood viscosity and inflammation, Haematologica. 96(11) (2011), 1589-1594.

[69] A. Nitsche, Raynaud, digital ulcers and calcinosis in scleroderma, Reumatol Clin 8(5)(2012), $270-277$.

[70] K. Parthasarathi and H.H. Lipowsky, Capillary recruitment in response to tissue hypoxia and its dependence on red blood cell deformability, Am J Physiol 277 (1999), H2145-H2157.

[71] S. Pérez, A. Milani, L. Acosta and R.J. Rasia, New evidence of red blood cell rheological disorders in beta-thalassaemia minor, Clin Hemorheol Microcirc 31(2) (2004), 89-96.

[72] S. Perrotta, P.G. Gallagher and N. Mohandas, Hereditary spherocytosis, Lancet. 372(9647) (2008), 1411-1426.

[73] S. Rabhi, H. Benjelloune, M. Meziane, M. Amrani, R. Berrady, O. Mikou, F.Z. Mernissi and W. Bono, Hereditary spherocytosis with leg ulcers healing after splenectomy, South Med J 104(2) (2011), 150-152.

[74] M. Ramos-Casals, J.H. Stone, M.C. Cid and X. Bosch, The cryoglobulinaemias, Lancet 379(9813) (2012), $348-360$.

[75] H.L. Reid and K. De Ceulaer, Abnormal plasma and serum viscosity in systemic lupus erythematosus (SLE): A Jamaican study, Clin Hemorheol Microcirc 20(3) (1999), 175-180.

[76] W.O. Richter, P. Jahn, N. Jung, E. Nielebock and H. Tachezy, Fibrinogen adsorption in the diabetic foot syndrome and peripheral arterial occlusive disease: First clinical experience, Ther Apher 5(5) (2001), 335-339.

[77] H. Rietzsch, I. Panzner, T. Selisko, U. Julius, N. Jabs, M. Reimann, E. Bonifacio, M. Bornhäuser and S.R. Bornstein, Heparin-induced Extracorporal LDL precipitation (H.E.L.P) in diabetic foot syndrome - preventive and regenerative potential? Horm Metab Res 40(7) (2008), 487-490. 
[78] V. Rieu, P. Cohen, M.H. André, L. Mouthon, P. Godmer, B. Jarrousse, F. Lhote, F. Ferrière, P. Dény, P. Buchet and L. Guillevin, Characteristics and outcome of 49 patients with symptomatic cryoglobulinaemia, Rheumatology (Oxford) 41(3) (2002), 290-300.

[79] H.R. Roberts, T.E. Stinchcombe and D.A. Gabriel, The dysfibrinogenaemias, Br J Haematol 114(2) (2001), $249-257$.

[80] R.S. Rosenson, S. Shott and R. Katz, Elevated blood viscosity in systemic lupus erythematosus, Semin Arthritis Rheum 31(1) (2001), 52-57.

[81] P. Rubegni, M.L. Flori, M. Fimiani and L. Andreassi, A case of cryofibrinogenaemia responsive to stanozolol, $\mathrm{Br} J$ Haematol 93(1) (1996), 217-219.

[82] E. Ruzzon, M.L. Randi, F. Tezza, G. Luzzatto, R. Scandellari and F. Fabris, Leg ulcers in elderly on hydroxyurea: A single center experience in Ph-myeloproliferative disorders and review of literature, Aging Clin Exp Res 18(3) (2006), $187-190$.

[83] D. Saadoun, I. Elalamy, P. Ghillani-Dalbin, D. Sene, A. Delluc and P. Cacoub, Cryofibrinogenemia: New insights into clinical and pathogenic features, Am J Med 122(12)(2009), 1128-1135.

[84] K. Sakieda, Y. Sumikawa, K. Imaoka, S. Murata, C. Nakamura, K. Mizumoto, H. Niihara, K. Takagaki and E. Morita, Successful treatment of leg ulcer caused by cryofibrinogenemia by using a systemic corticosteroid and warfarin, Int J Dermatol 50(12) (2011), 1538-1541.

[85] Z. Sandouk, Z. Alirhayim, S. Hassan and W. Qureshi, Cryofibrinogenaemia: Not just skin deep, BMJ Case Rep 2013 (2013).

[86] R. Satta, G. Casu, F. Dore, M. Longinotti and F. Cottoni, Follicular spicules and multiple ulcers: Cutaneous manifestations of multiple myeloma, J Am Acad Dermatol 49(4) (2003), 736-740. 8

[87] C.S. Seitz, N. Berens, E.B. Bröcker and A. Trautmann, Leg ulceration in rheumatoid arthritis-an underreported multicausal complication with considerable morbidity: Analysis of thirty-six patients and review of the literature, Dermatology 220(3) (2010), 268-273.

[88] V.K. Shanmugam, V.D. Steen and T.R. Cupps, Lower extremity ulcers in connective tissue disease, Isr Med Assoc J 10(7) (2008), 534-536.

[89] S.E. Shapiro, E. Phillips, R.A. Manning, C.V. Morse, S.L. Murden, M.A. Laffan and A.D. Mumford, Clinical phenotype, laboratory features and genotype of 35 patients with heritable dysfibrinogenaemia, Br J Haematol 160(2) (2013), 220-227.

[90] F.B. Smith, G.D. Lowe, A.J. Lee, A. Rumley, G.C. Leng and F.G. Fowkes, Smoking, hemorheologic factors, and progression of peripheral arterial disease in patients with claudication, J Vasc Surg 28(1) (1998), 129-135.

[91] P.C. Smith, The causes of skin damage and leg ulceration in chronic venous disease, Int J Low Extrem Wounds 5(3) (2006), 160-168.

[92] T. Taniguchi, Y. Asano, M. Hatano, Z. Tamaki, M. Tomita, T. Kawashima, M. Miyazaki, H. Sumida, K. Akamata, T. Takahashi, Y. Ichimura, T. Toyama, M. Sugita, S. Noda, A. Yao, K. Kinugawa and S. Sato, Effects of bosentan on nondigital ulcers in patients with systemic sclerosis, Br J Dermatol 166(2) (2012), 417-421.

[93] J.G. Taylor 6th, V.G. Nolan, L. Mendelsohn, G.J. Kato, M.T. Gladwin and M.H. Steinberg, Chronic hyper-hemolysis in sickle cell anemia: Association of vascular complications and mortality with less frequent vasoocclusive pain, PLoS One 3(5) (2008), e2095.

[94] E. Terpos, M. Samarkos, C. Meletis, E. Apostolidou, M. Tsironi, K. Korovesis, D. Mavrogianni, N. Viniou and J. Meletis, Unusual association between increased bone resorption and presence of paroxysmal nocturnal hemoglobinuria phenotype in multiple myeloma, Int J Hematol 78(4) (2003), 344-348.

[95] O.A. Thurtle, M.I. Cawley, The frequency of leg ulceration in rheumatoid arthritis: A survey, J Rheumatol 10(3) (1983), 507-509.

[96] J. Tripette, T. Alexy, M.D. Hardy-Dessources, D. Mougenel, E. Beltan, T. Chalabi, R. Chout, M. Etienne-Julan, O. Hue, H.J. Meiselman and P. Connes, Red blood cell aggregation, aggregate strength and oxygen transport potential of blood are abnormal in both homozygous sickle cell anemia and sickle-hemoglobin C disease, Haematologica 94 (8) (2009), 1060-1065.

[97] A.G. Tsai, C. Acero, P.R. Nance, P. Cabrales, J.A. Frangos, D.G. Buerk and M. Intaglietta, Elevated plasma viscosity in extreme hemodilution increases perivascular nitric oxide concentration and microvascular perfusion, Am J Physiol Heart Circ Physiol 288 (2005), H1730-1739.

[98] A.G. Tsai, B. Friesenecker, M. McCarthy, H. Sakai and M. Intaglietta, Plasma viscosity regulates capillary perfusion during extreme hemodilution in hamster skinfold model, Am J Physiol 275 (1998), H2170-2180.

[99] A.Undas, Acquired dysfibrinogenemia in atherosclerotic vascular disease, Pol Arch Med Wewn 121 (2011), 310-319.

[100] S. Varma, N. Varma, V.V. Reddy, S. Naseem, P. Bose and P. Malhotra, Detection of paroxysmal nocturnal hemoglobinuria-phenotype in patients with chronic lymphocytic leukemia and multiple myeloma, Indian J Pathol Microbiol 55(2) (2012), 206-210. 
[101] A. Vayá, J. Iborra, C. Falcó, I. Moreno, P. Bolufer, F. Ferrando, M.L. Pérez and J. Aznar, Rheological behaviour of red blood cells in beta and deltabeta thalassemia trait, Clin Hemorheol Microcirc 28(2) (2003), 71-78.

[102] J.D. Vuerstaek, S.W. Reeder, C.J. Henquet and H.A. Neumann, Arteriolosclerotic ulcer of Martorell, J Eur Acad Dermatol Venereol 24(8) (2010), 867-874.

[103] D.M. Wahezi, N.T. Ilowite, K.M. Kenney-Riley and P.F. Belamarich, Chronic leg ulceration as the presenting feature of diffuse systemic sclerosis in childhood, J Pediatr 159(4) (2011), 698.

[104] W.Q. Wang, X.Y. Zhao, H.Y. Wang and Y. Liang, Increased fatty acid synthase as a potential therapeutic target in multiple myeloma, J Zhejiang Univ Sci B 9(6) 2008,441-447.

[105] N. Weiss, A critical review on the use of lipid apheresis and rheopheresis for treatment of peripheral arterial disease and the diabetic foot syndrome, Semin Dial 25(2) (2012), 220-227.

[106] T. Winkens, A. Pfeil, B. Theis and C. Jung, Cryofibrinogenemia associated with cryoglobulinemia-a severe case with amputation of four extremities, Jpn J Clin Oncol 44(10) (2014), 1013-1014.

[107] Y.-T. Wu, A. Chiou and C.-W. Sun, Correlation between tissue oxygenation and erythrocytes elasticity, J Biophotonics 4 (2011), 224-228.

[108] T. Yamazaki, T. Akimoto, K. Okuda, T. Sugase, E. Takeshima, A. Numata, Y. Morishita, Y. Iwazu, H. Yoshizawa, T. Komada, K. Iwazu, O. Saito, F. Takemoto, S. Muto and E. Kusano, Purpura with ulcerative skin lesions and mixed cryoglobulinemia in a quiescent hepatitis B virus carrier, Intern Med 53(2) (2014), 115-119. 